\title{
fMRI of the auditory system
}

Citation for published version (APA):

Di Salle, F., Esposito, F., Scarabino, T., Formisano, E., Marciano, E., Saulino, C., Cirillo, S., Elefante, R., Scheffler, K., \& Seifritz, E. (2003). fMRI of the auditory system: understanding the neural basis of auditory gestalt. Magnetic Resonance Imaging, 21(10), 1213. https://doi.org/10.1016/j.mri.2003.08.023

\section{Document status and date:}

Published: 01/01/2003

DOI:

10.1016/j.mri.2003.08.023

Document Version:

Publisher's PDF, also known as Version of record

\section{Document license:}

Taverne

\section{Please check the document version of this publication:}

- A submitted manuscript is the version of the article upon submission and before peer-review. There can be important differences between the submitted version and the official published version of record.

People interested in the research are advised to contact the author for the final version of the publication, or visit the DOI to the publisher's website.

- The final author version and the galley proof are versions of the publication after peer review.

- The final published version features the final layout of the paper including the volume, issue and page numbers.

Link to publication

\footnotetext{
General rights rights.

- You may freely distribute the URL identifying the publication in the public portal. please follow below link for the End User Agreement:

www.umlib.nl/taverne-license

Take down policy

If you believe that this document breaches copyright please contact us at:

repository@maastrichtuniversity.nl

providing details and we will investigate your claim.
}

Copyright and moral rights for the publications made accessible in the public portal are retained by the authors and/or other copyright owners and it is a condition of accessing publications that users recognise and abide by the legal requirements associated with these

- Users may download and print one copy of any publication from the public portal for the purpose of private study or research.

- You may not further distribute the material or use it for any profit-making activity or commercial gain

If the publication is distributed under the terms of Article $25 \mathrm{fa}$ of the Dutch Copyright Act, indicated by the "Taverne" license above, 


\title{
fMRI of the auditory system: understanding the neural basis of auditory gestalt
}

\author{
Francesco Di Salle $^{\mathrm{a}, *}$, Fabrizio Esposito ${ }^{\mathrm{b}}$, Tommaso Scarabino ${ }^{\mathrm{c}}$, Elia Formisano ${ }^{\mathrm{d}}$, \\ Elio Marciano ${ }^{\mathrm{e}}$, Claudio Saulino ${ }^{\mathrm{e}}$, Sossio Cirillo ${ }^{\mathrm{f}}$, Raffaele Elefante ${ }^{\mathrm{a}}$, Klaus Scheffler ${ }^{\mathrm{g}}$, \\ Erich Seifritz \\ ${ }^{a}$ Department of Neurological Sciences, University of Naples, Federico II Naples, Italy \\ ${ }^{\mathrm{b}}$ Second Division of Neurology, Second University of Naples, Naples, Italy \\ ${ }^{\mathrm{c}}$ Department of Neuroradiology, Scientific Institute Casa Sollievo della Sofferenza, S. Giovanni Rotondo, Foggia, Italy \\ ${ }^{\mathrm{d}}$ Department of Cognitive Neuroscience, Maastricht University Maastricht, The Netherlands \\ ${ }^{\mathrm{e}}$ Audiological Unit, University of Naples, Federico II, Naples, Italy \\ ${ }^{\mathrm{f}}$ Department of Neuroradiology, Second University of Naples, Naples, Italy \\ ${ }^{\mathrm{g}}$ Magnetic Resonance Center Biozentrum, University of Basel, Basel, Switzerland \\ ${ }^{\mathrm{h}}$ Department of Psychiatry, University of Basel, Basel, Switzerland
}

Received 15 August 2003; received in revised form 22 August 2003; accepted 23 August 2003

\begin{abstract}
Functional magnetic resonance imaging (fMRI) has rapidly become the most widely used imaging method for studying brain functions in humans. This is a result of its extreme flexibility of use and of the astonishingly detailed spatial and temporal information it provides. Nevertheless, until very recently, the study of the auditory system has progressed at a considerably slower pace compared to other functional systems. Several factors have limited fMRI research in the auditory field, including some intrinsic features of auditory functional anatomy and some peculiar interactions between fMRI technique and audition. A well known difficulty arises from the high intensity acoustic noise produced by gradient switching in echo-planar imaging (EPI), as well as in other fMRI sequences more similar to conventional MR sequences. The acoustic noise interacts in an unpredictable way with the experimental stimuli both from a perceptual point of view and in the evoked hemodynamics. To overcome this problem, different approaches have been proposed recently that generally require careful tailoring of the experimental design and the fMRI methodology to the specific requirements posed by the auditory research. The novel methodological approaches can make the fMRI exploration of auditory processing much easier and more reliable, and thus may permit filling the gap with other fields of neuroscience research. As a result, some fundamental neural underpinnings of audition are being clarified, and the way sound stimuli are integrated in the auditory gestalt are beginning to be understood. (C) 2003 Elsevier Inc. All rights reserved.
\end{abstract}

Keywords: Functional MRI; Auditory cortex

\section{Introduction}

In the short period of a decade since its first description [1-3], functional magnetic resonance imaging (fMRI), using the blood-oxygenation level dependent (BOLD) signal contrast, has become one of the key technologies in neuroscience. It has opened entirely new avenues for the study of human brain functions, which have substantially increased the knowledge about functional neuroanatomy of the human 3581.

* Corresponding author. Tel.: +39-081-746-2883; fax: +39-081-746-

E-mail address: disalle@unina.it (F. Di Salle). brain, and have begun unraveling some fine mechanisms operating at the level of the single functional systems or governing the interaction between different systems. This is mainly because of its sensitivity in analyzing brain functional phenomena and of the lack of biological invasiveness, resulting in unprecedented and unparalleled flexibility of use. The decisive advantage of fMRI, compared to the other functional neuroimaging methods, consists mainly of the unsurpassed spatial resolution that is in the range of the fractions of millimeters. Furthermore, compared to the methods using nuclear tracers [positron emission tomography (PET) or single photon emission computed tomography (SPECT)], fMRI provides much higher temporal resolution 
(in the range of $100 \mathrm{~ms}$ or less) and an inherent coregistration to same-session structural studies with high anatomic detail.

As an additional advantage, fMRI studies do not require the analysis of a group of volunteers but can produce valuable results at the level of single individuals, while the latter is more difficult with tracer-based functional neuroimaging methods. The analysis of single volunteers is crucial for studying small structures which show strong inter-individual variation [4], as is true for the auditory cortex. In that case, averaging data across different subjects and normalizing them into a standard stereotactic system, such as that proposed by Talairach and Tournoux [5], might well be associated with significant loss of information.

The ultimate goal of most functional brain mapping studies is to describe the regional and temporal nature of neuronal events. As a disadvantage of fMRI, neuronal activity is not measured directly, but instead by means of the hemodynamic effect associated with activation through a neurovascular "coupling" composed of a cascade of complex and poorly understood mechanisms [6].

This limits the temporal resolution of fMRI to be orders of magnitude poorer than that of electroencephalography (EEG) or magnetoencephalography (MEG), and the resolution in space faces a natural blurring and misregistration of the spatial sources of the BOLD signal, which differ slightly from the neuronal source location [7], since hemodynamic events can be somewhat dislocated compared to the neural events. However, the complexity of the physiological scenario underlying fMRI phenomena permits creative implementation of experimental fMRI paradigms allowing us to consistently expand the potential of MRI in identifying the anatomic sources [8] of the electrophysiological events together with their temporal behavior.

As an example, the use of the initial dip in the fMRI signal, instead of the large positive BOLD effect, has permitted the spatial resolution of fMRI to be pushed below the millimeter toward the dimensional range of the iso-orientation cortical columns, at least in the visual cortex of the cat at high field strengths [9].

Nevertheless, until very recently, the study of the auditory system has proceeded at a considerably slower speed compared to other functional systems. This is due to several factors, including the intrinsic anatomy of the auditory system and some peculiar interactions between audition and fMRI technique.

As concerns the functional anatomy of the auditory system, the reduced extension in space and the inter-individual variability of Heschl's region represent certain difficulties. The specific difficulties in the study of audition through fMRI arise mainly from the loud acoustic noise the gradient system produces during echo-planar and other functional image acquisition. This considerable background noise can interfere with the experimental stimuli in an unpredictable way. Among the many effects derived from this interference, the most expected one occurs in the partial saturation of neural excitation-evoked regional hemodynamics that reduces, probably in a nonlinear fashion, the BOLD signal amplitude in response to auditory stimuli. To overcome these problems, different approaches have recently been proposed, which generally require a careful tailoring of the experimental designs, the fMRI methodology, and the strategies of data processing to the specific problems of audition and the particular research goal.

This article reviews the present state of fMRI research on audition, examining the solutions already existing and those under development to the specific problems of auditory fMRI. The increasing knowledge about the auditory system, derived in part from fMRI research, has already opened new avenues in the comprehension of basic and high level neural processes in audition.

\section{Anatomic organization of the auditory system}

The functional anatomy of the auditory system poses specific problems to fMRI analysis. First, the central auditory system includes a large ensemble of subcortical nuclei, connected each other and with the auditory cortex through ascending and descending white matter fiber pathways, subserving both serial and parallel information processing within the auditory system. Two main ascending tracts subserve both tonotopic and nontonotopic (polysensory) functions.

The first nucleus the auditory nerve projects to is the cochlear nucleus in the brainstem. Most auditory pathway fibers cross the midline to form the lateral lemniscus on the contralateral side, while a few fibers do not cross the midline, passing ipsilaterally in the same way as those on the contralateral side.

They project, via the superior olivary complex, to the central nucleus of the inferior colliculus. All ascending auditory information is channeled through the central nucleus of the inferior colliculus. It connects the superior colliculus and other motor centers of the brain in order to control eye movements and other motor responses to auditory stimuli. The output of the inferior colliculus, through the brachium of the inferior colliculus, reaches the medial geniculate body, which is the thalamic auditory relay station. The medial geniculate body is divided into three portions: a ventral, a dorsal, and a medial one. The ventral portion, receiving input from the central nucleus of the inferior colliculus, is part of the "tonotopic" ascending auditory pathway and contains laminae with neurons that prefer similar frequencies. On the other hand, the dorsal and medial portions of the medial geniculate receive input from all the tonotopic and nontonotopic divisions of the inferior colliculus as well as from visual and sensory areas, and thus participate within the "polysensory" pathways [10].

Interestingly, the number of fiber connections increases from caudal to cranial. The inferior colliculus has about 250,000 fibers, ten times more than the number of fibers in 


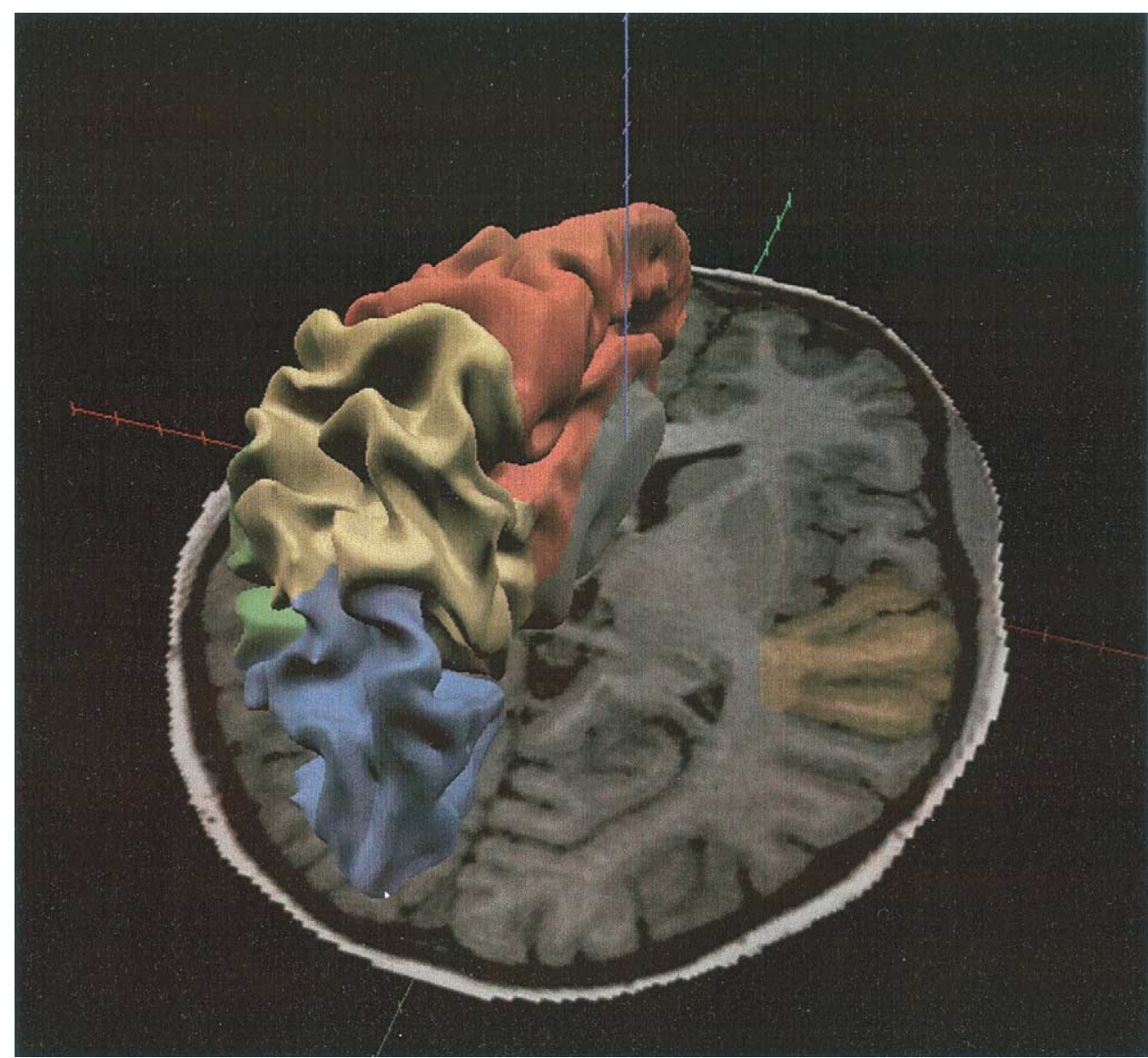

Fig. 1. 2-D and 3-D representation of the brain, showing in the left hemisphere the axial anatomy of the temporal lobe. Temporal structures are highlighted in light brown color.

the auditory nerve. This increase in fiber number indicates that considerable signal processing occurs within the pathway from the auditory nerve to the auditory cortex [11]. In fact, each subcortical station presents multiple connections to other subcortical structures, subserving this rich subcortical processing of auditory information whose main purpose is probably the integration of information from both ears (e.g., analyzing the arrival times and their relative sound intensities).

The functional parcellation of sound processing into the rich network of subcortical stations is far more problematic than a "centralized" processing within a single cortical area from the perspective of functional neuroimaging. Here the rules governing the functional parcellation of auditory information processing and the mechanisms and features of the functional interactions between different subcortical and cortical processing stations represent separate and additional problems for functional neuroimaging. Furthermore, the parcellation itself into tiny structures, like the subcortical nuclei are, is a substantial challenge for neuroimaging methods, where spatial resolution is not an easy and costless feature. Some techniques have been proposed to overcome the difficulties created by the parcellation of subcortical auditory processing into tiny and interacting structures. Among these techniques it is worth considering the methods that try to reduce the deterioration of fMRI signal in superficial structures by suppressing the effect of cerebrospinal fluid pulsations with a synchronization of image acquisition to the cardiac cycle.

As a further difficulty, converging results from studies of cortical cyto-architecture, myelo-architecture, and chemoarchitecture [12], microelectrode recordings and lesion studies indicate that, in primates, the central processing of sounds and words is performed by a complex and interconnected array of cortical areas. This array is localized mainly at the superior surface of the temporal lobe (Fig. 1), along the inferior margin of the lateral fissure, and is normally hidden from view by the overlying superior operculum. The superior temporal surface is formed by the superior temporal gyrus (STG). This runs parallel to the lateral fissure, forms the temporal operculum, and constitutes a large cortical area arranged along the lower bank of the lateral fissure. The superior surface of the STG can be divided into three parts. From front to back these are the planum polare, the transverse temporal gyri (of Heschl), and the planum temporale [13] (Fig. 2).

The gyri directly involved in auditory perception are the transverse temporal gyri (of Heschl). Heschl's gyri are one or more gyri coursing obliquely across the superior surface of the temporal lobe. These gyri exhibit marked numerical 


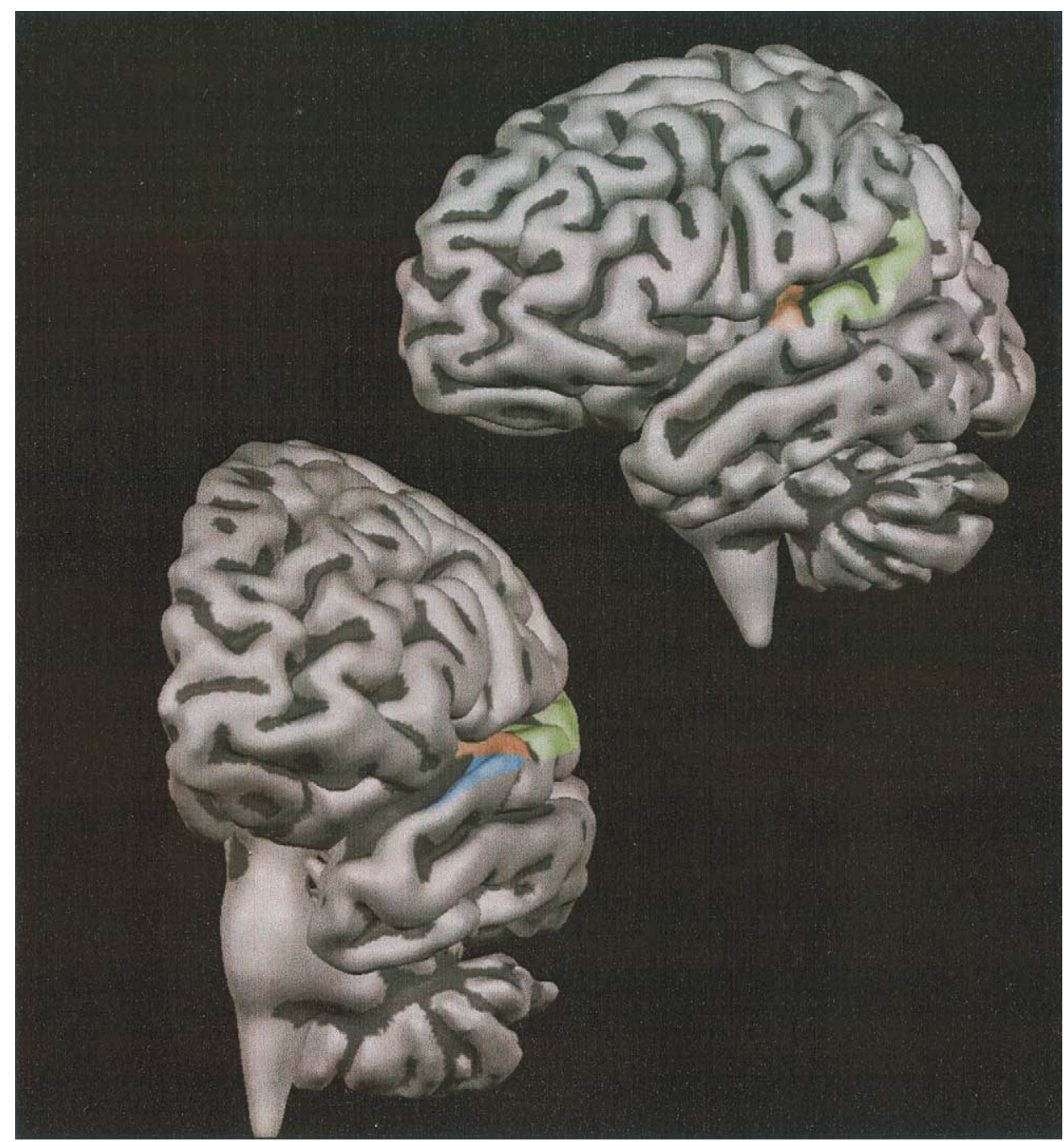

Fig. 2. 3-D surface representation of the brain. The gyral pattern of the left hemisphere of the standard brain from the Montreal Neurologic Institute (MNI) has been reconstructed using BrainVoyager (www.brainvoyager.de). The superior temporal surface is examined from a lateral and a frontal viewpoint, showing the presence of three main gyral components: Heschl gyrus (in light brown color) is surrounded anteriorly by the planum polare (light blue color) and posteriorly by the planum temporale (in light green color).

variability among individuals, the most common configuration being of one transverse gyrus in the left and two in the right hemisphere (48\%) [14]. The anterior gyrus (first gyrus of Heschl) corresponds to Brodmann area (BA) 41, and is separated caudally from the (incostant) posterior (second) gyrus of Heschl (BA 42) by the intermediate transverse temporal sulcus [14]. More caudally, the transverse temporal sulcus separates the region of Heschl from the planum temporale, while ventral (anterior) to the first Heschl's gyrus the superior temporal surface is called planum polare [13]. BA 22, which is believed to perform nonprimary auditory processing, partially encompasses the planum temporale, the planum polare, and the posterior and lateral extensions from Heschl's gyri $[13,15]$.

Primary auditory perception is thought to be located in the first transverse temporal gyrus (first Heschl's gyrus), where a "core" or center for auditory processing has been identified in nonhuman primates. This core contains two
$[16,17]$ or three $[18,19]$ primary-like fields with koniocortical organization in only $\sim 15 \mathrm{~mm}$ of linear extension. The primary-like fields show a specific correspondence between cortical topography and sound frequencies, i.e., a precise "tonotopic organization." Three tonotopical fields are identified within the core: a caudal primary area (A1); a rostrolateral area (RL); and a rostrotemporal area (RT) [16]. This anatomic organization, and the evidence that selective ablation of A1 does not abolish pure tone sensitivity, suggests that auditory information is processed in series from the medial geniculate nucleus to the core, and in parallel within the three core fields [20].

The auditory "core" is surrounded by a "belt" region, which displays a less typical cytoarchitecture called parakoniocortex, appears to perform a higher level of processing, and is divided into several functional fields [16-22]. The functional properties of the auditory belt are thought to resemble those known to exist in the nonprimary visual 
areas, where neurons integrate visual information spatially over larger receptive fields and respond preferentially to complex visual stimuli. In the same way, neurons belonging to the nonprimary centers of the auditory belt tend to respond poorly and inconsistently to conventional pure-tone stimuli. Instead, they present stronger and specific responses to bandpassed noise bursts [21,22]. It has proven difficult to demonstrate functional parcellation of the belt region in the absence of a tonotopic criterion. However, microelectrode studies in nonhuman primates suggest that at least seven separate auditory areas are present in the belt and are involved primarily in the processing of complex sounds [19].

Surrounding the belt region, mainly along the lateral surface of the STG, the auditory "parabelt" exhibits homotypical cytoarchitecture and associative functions. The primary auditory cortex is connected to a sensory speech processing area in the dorsal STG of the same hemisphere (Wernicke's area). Wernicke's area is partially coincident with BA 22 and extends backwards and upwards to the gyrus supramarginalis. The primary auditory cortex is also connected to a motor speech processing area (Broca's area) which corresponds to BA 44 and 45 in the posterior inferior frontal lobe (pars opercularis of the inferior frontal gyrus). Recent electrophysiological and tract tracing studies in nonhuman primates indicate separate auditory streams originating in the auditory cortex and connected to spatial and nonspatial frontal cortical domains, similar to the ventrolateral object ("what") and dorsolateral spatial ("where") processing domains of the visual system in the prefrontal cortex $[23,24]$.

\section{Measuring the auditory system BOLD response with fMRI}

\subsection{Technical considerations}

In the study of auditory processing, the acquisition as well as the analysis techniques play a key role, probably more critical than in the exploration of other brain functions. This is a consequence of the functional parcellation and of the complexity of auditory central processing, which require high spatial resolution analysis techniques. But a particular feature of the echo planar imaging (EPI) and other fast BOLD-sensitive sequences poses the most demanding problem to functional exploration of audition; it is the loud banking noise the magnetic field gradients produce each time they are switched on and off during image acquisition. This noise reaches sound pressure levels (SPL) in the range of about $100 \mathrm{~dB}$, depending on factors such as the specific imaging sequence, type of gradients, brand of scanner, and size of the subject examined [25]. The noise which results from the EPI itself activates the auditory system [26-28], and interacts unpredictably with the true experimental stimuli during studies of functional activation tasks such as hearing threshold of experimental stimuli [29], phonetic
[30], and foreground-background discrimination [31]. Therefore, contamination of the response to an experimental auditory stimulus by environmental noise within the bore of the magnet is of great concern.

The scanner banking produces a constant neuronal stimulation within the auditory system. The resulting activation is present during both the on and off periods of typical experimental blocks of a boxcar design and requires adequate consideration of the actual baseline in event-related design. Considering as true the hypothesis of "the pure insertion" [32], with a simple additive interaction between temporally concurrent stimuli, this may not represent a primary problem for functional MRI. But in case the neural response to a concurrent auditory stimulation does not add up linearly to the neural response to MRI noise, then an unpredictable modulation of the activity resulting from the interaction may strongly impair the reliability of the subsequent inferential statistical mapping.

Several strategies have been proposed to overcome this intrinsic problem of auditory fMRI. These methods can be divided into three categories. One approach is to use silent MRI sequences, which generate a sound level far below that of the experimentally delivered stimuli. Another approach consists of strongly reducing the noise perceived by the volunteers by means of passive or active noise reduction devices. The third possibility takes advantage of the delayed onset of the BOLD signal change which follows acoustic stimulation, and thereby separate the EPI noise from the experimental stimuli.

\subsection{Silent sequences for BOLD imaging}

The scanner noise arises from the gradient coil, when pulses of current are passed through it for spatial encoding of the MR signal. Since the gradient coil is placed inside a strong magnetic field, a pulsed Lorenz force is induced. This force vibrates the coil structure, which in turn generates a compression wave in the air that is perceived as the "scanner noise." Hedeen and Edelstein [25] have shown that the response of a MRI gradient system to pulsed currents is linear. As a consequence, the sound spectrum generated by a particular gradient current waveform is the product of the frequency response of the gradient system and the Fourier transform of the waveform. The principle of silent sequences is to use gradient current waveforms that contain no frequencies for which the response of the gradient coils' transfer function is high. Such band-limited pulse shapes can be designed using soft or sinusoidal ramps for all three gradient axes [33]. This approach is not applicable to EPI sequences, but can be suitable for alternative fast acquisition techniques (FLASH sequences). This procedure can provide very strong noise reduction, reaching noise levels as low as $40 \mathrm{~dB}$, at the cost of a sensible prolongation of acquisition times (several seconds for each image slice), which makes multislice acquisition difficult to realize.

A further approach to generate silent and rapid sequences 
is based on the BURST technique [34,35]. A train of excitation pulses is applied during a single, constant gradient. This RF-burst generates a train of echoes that can be acquired with a second, single read-out gradient. As a result, this technique does not require rapidly switched gradients, reducing imaging noise to about $40-50 \mathrm{~dB}$. Compared to EPI, silent BURST offers a nearly identical imaging speed. However, signal-to-noise is about 5 to 10 times lower than for EPI.

\section{Noise attenuation}

Diminishing scanner noise is possible by means of passive and active noise attenuation. The easiest solution to noise attenuation is to adopt passive devices to reduce gradient noise: the combined use of ear muffs and ear plugs can attenuate noise up to $40-50 \mathrm{~dB}$, depending on the material they are composed of and the specific frequency spectrum of gradient noise. Even the best combinations of these factors are thought to be incompatible with stronger attenuations, due to the presence of noise conduction through body tissues to the middle ear. This mechanism of noise conduction is far less efficient than air conduction but can account for approximately $50 \mathrm{~dB}$ sound level when air conduction is reduced, and is not eliminated unless the entire body of the volunteer is isolated. So a further reduction of air conducted noise can even make the body tissue conducted noise more audible.

An alternative to passive noise attenuation is the use of active devices. In this approach, neural networks consisting of cascaded time-delays are used as predictors of feedback to an active noise control system. This latter produces phase-reversed noise emissions, the frequency spectrum of which tries to match as completely as possible the spectrum of gradient noise, leading to a partial noise cancellation. If the cancellation noise is emitted inside the earmuffs, this technique is limited in its efficacy again by the body tissues noise conduction. It is thought that cancellation efficacy higher than 20-30 dB [36] is difficult to obtain. The production of noise emissions outside earmuffs exactly phasereversed to the gradient noise components traveling through the body is a very complex problem. In this case, however, the active noise reduction could act additively to the passive one, not being limited by body conduction and so permitting to reach noise cancellations higher than 50-60 dB [37].

\subsection{Separation of EPI scanner noise and experimental noise}

The third approach to the reduction of the influence of gradient noise stimulation on the activity of auditory cortex consists of separating scanner noise from auditory stimuli through a particular choice of experimental parameters. This approach takes advantage of the temporal delay separating a neural stimulation from its hemodynamic effects.
Typically, the BOLD signal change induced by a neuronal stimulation appears only after a delay, on the order of seconds. And the decay of the BOLD signal to the baseline equilibrium takes at least $10 \mathrm{~s}[33,38]$. The delay in the hemodynamic response function can be used to disentangle EPI noise from additional acoustic stimuli. A multislice echo-planar slab covering the auditory cortex can be sampled a few times-after an auditory stimulation, before the corresponding BOLD signal decays completely, and before the BOLD response to the gradient noise appears. Using this approach requires attention to two considerations: 1) the separation of successive acquisition blocks should be long enough to allow the auditory system to recover from the response to the preceding noise-producing EPI acquisition; and 2) the scan period should be short enough not to pick up the rising limb of the BOLD response to the gradient noise. Assuming a delay time of about $2 \mathrm{~s}$ between the stimulus onset and the BOLD response, and a dispersion time of about $10 \mathrm{~s}$, one might use scanning times shorter than about $2 \mathrm{~s}$ and repetition times (TRs) of about $15 \mathrm{~s}$ or longer [39-42]. The intermittent scanning approach has been termed "clustered" [43] or "sparse" [44] sampling, and is similar to averaged single trial sampling modes with varying delays between stimulus and scans $[28,45,46]$. Using long-enough TRs, the latter technique allows for single event-related fMRI experiments in silence. An obvious disadvantage is that this procedure is very time-consuming.

A comparable approach to separating scanner from experimental noise is to deliver the stimulus prior to a continuously running EPI acquisition. That is, a stimulus is applied for a certain time, and images are acquired after the stimulus has been turned off to pick up the falling limb of the BOLD signal curve. The measured signal time course at the beginning of the continuously running EPI measurements, however, is strongly biased by the $\mathrm{T}_{1}$-related saturation caused by the rapidly applied excitation pulses. To control for the saturation decay, scans with and without preceding experimental acoustic stimulation can be subtracted. This technique has been used to map the BOLD response to the EPI noise [27], to experimental sine tones [47], and to motor tasks [48]. An elegant way to separate the $\mathrm{T}_{1}$-related decay from the significantly weaker BOLD signal change is to prepare the EPI acquisition with preceding, silent saturation pulses [49].

\section{Basic auditory processing}

\subsection{Response to sine tones}

Although gradient noise produces an unwanted activation of the auditory system and interacts heavily with experimental stimuli [27], it has been shown that speech and other acoustic stimuli produce a reliable BOLD signal even in the presence of gradient noise [50]. The BOLD response to auditory stimuli depends on many factors. Its strength 
correlates positively with the sound pressure level of the experimental stimuli [51], with the subject's attention to the stimuli [52], and with the presentation rate [53,54].

The administration of pulsed sine tones is a simple method for activating Heschl's gyrus and the planum temporale reliably enough that pulsed sine tones have been used, even for clinical applications, to examine the binaural interaction of auditory processing.

In fact, in unilateral deaf patients, the monaural stimulation of the intact ear determines a bilaterally balanced BOLD response, with a lateralization ratio between the left and right hemispheres that is just 1.3 greater contralateral to the healthy ear. Normal-hearing subjects, on the contrary, show a strong lateralization (3.4-5.2) of BOLD response contralateral to the side of monaural stimulation. These data seem to indicate a reorganization of the auditory pathways of unilateral deaf patients.

Consistent with these findings, the BOLD response to unilateral acoustic stimulation is greater in the ipsilateral cochlear nucleus than in the contralateral cochlear nucleus, but the response in the inferior colliculus, the medial geniculate body, and the auditory cortex are mainly contralateral [55]. This difference suggests that the major decussation of the auditory pathway occurs below the inferior colliculi. These fMRI findings are consistent with electroencephalographic data [56], and are believed to subserve sound localization in space [57].

Few studies have focused on BOLD activation of subcortical structures. Most noninvasive methods for brain mapping have limited success in visualizing functional changes in the brainstem. Of these, MRI appears to have the greatest potential. The limitations are due to the small size of the structures of interest, intrinsic motion of the structures related to cardiac pulsations, and severe artifacts related to the close proximity of bone, air, vessels, and brain that have very different magnetic susceptibilities. Image acquisition modes that are gated to the cardiac cycle partly overcome cardiac motion artifacts. Using gated imaging techniques, it is possible to measure the BOLD signal within the inferior colliculi in both normal subjects [58] and patients with tinnitus [55].

Since auditory percept mainly becomes understandable through the analysis of its temporal dimension, it has become progressively clear that a special memory "module" must exist, able to provide a very short term temporal integration of single auditory events. This function, called "auditory sensory memory" or "echoic memory," is operating even before attention, does not even require consciousness, and indications about its activity are visible in EEG exams, where it is pinpointed by the phenomenon of the "mismatch negativity" [59]. A very recent fMRI study has discovered the neural bases of the echoic memory, which has a very precise anatomic basis correspondent to the right temporal plane [60].

\section{2. fMRI of human tonotopic organization}

Studies performed in several species have recognized an ordered representation of sound frequencies (tonotopy) in the superior surface of the temporal lobe, in one or more tonotopic "primary-like" areas [16,61-64]. Less clear, and even sometimes controversial $[65,66]$, the evidence of a tonotopic organization of auditory cortex in humans has been suggested by the study of auditory-evoked potentials. These studies demonstrated a posteromedial to anterolateral representation of increasing sound frequencies [67-72]. Probably the finest-tuned tonotopic mapping of the human auditory cortex was achieved at the single unit level by Howard and colleagues [73]. Using chronic microelectrodes implanted in patients for epilepsy surgery, these authors documented that the units responding to sound exhibited a frequency-dependent response pattern. The majority $(\sim 3 / 4)$ of the units manifested sharply tuned, frequency-related excitatory responses. A minority $(\sim 1 / 4)$ exhibited, instead, large receptive fields and excitatory responses to almost the entire range of frequencies. The tonotopic organization was characterized by a medio-caudal gradient related to increasing sound frequencies. Interestingly, the tonotopic representation seems to be reorganized in subjects with tinnitus [74].

PET studies suggest that regional changes in glucose metabolism and blood flow in response to a $4000 \mathrm{~Hz}$ sine tone stimulus lie posteromedial to those induced by a 500 $\mathrm{Hz}$ tone [75]. The tonotopic principle described above is supported by recent fMRI studies that found a bilateral medio-lateral, fronto-occipital, and cranio-caudal distribution in the portions of the auditory cortex which respond to different frequencies [76-82].

It is of note that most tonotopic studies have used steadystate acoustic stimuli rather than single short events, such as proposed by Yang et al. [82], although the time-related behavior of the auditory system remains largely unexplored. For instance, it is not known whether the same or distinct neuronal populations are recruited by short vs. sustained auditory stimuli. Furthermore, even using a 15-s delay in intermittent image acquisition modes, as described above (e.g., Bilecen et al. [76]) may present difficulties, because the next stimulus may interfere with prolonged post-peak undershoot components and, therefore, arrive before the hemodynamic state has fully recovered to baseline. As suggested by recent studies [83], future fMRI studies using sophisticated experimental designs, including event-related experiments, will yield a more detailed understanding of the human tonotopic organization.

\subsection{Sound localization and detection of sound movement}

In the brain, spatial decoding of an acoustic source relies on differences in the phase (arrival time) and the amplitude of a tone that reaches the two ears. Although the human primary auditory cortex is involved in analyzing the time structure of acoustic information [84], areas outside the 
primary auditory area appear to integrate and compare the interaural phase and amplitude of binaural sound [85]. fMRI has shown that this interaction is mediated by a network of areas outside the primary auditory fields [86,87], including bilateral premotor frontal cortex and parietal cortex $[88,89]$. Interestingly, a recent PET study [90] found that congenitally blind subjects recruit occipital areas usually involved in visual spatial orientation to achieve spatial orientation based on auditory cues, whereas sighted subjects do not. Further PET evidence suggests involvement of frontal areas in the analysis of auditory perception of objects and their spatial localization [24].

\subsection{Speech and language perception}

Recent fMRI evidence suggests that the central auditory system is equipped with a voice-selective area located in the upper bank of the superior temporal sulcus [91]. This area was activated more strongly by words and speech than by unstructured noise, and was activated by pseudowords and reversed speech, suggesting a role for acoustic rather than linguistic speech perception [92]. Such an area would be analogous to the face selective areas in the nonretinotopic visual association cortex involved in the mediation of recognition of human faces [93].

fMRI studies that map the areas involved in language processing support the classic models derived from lesion studies and show strongly lateralized cortical activation of the left hemisphere in the frontal, temporal, and parietal lobes [94]. They also provide evidence for temporoparietal language processing outside the classic areas, i.e., 1) outside Wernicke's area in the middle temporal, inferior temporal, fusiform and angular gyri; and 2) outside Broca's area in the left prefrontal cortex. Furthermore, the left frontal areas appear to be involved in receptive aspects of language processing. More recent fMRI work, using event-related designs, distinguishes between areas involved in syntactic and semantic language processing. Whereas syntactic processes activate areas in the planum polare bilaterally and in the left frontal operculum, normal speech is associated with bilateral activation in the primary auditory cortex and in adjacent areas of the superior temporal gyrus, not in the frontal cortex [95]. These data suggest that some automaticity of the linguistic processes is involved in normal speech comprehension, and that the left frontal and both temporal cortices play a role in comprehension of syntactic information [96].

Study of bilingual subjects has shown that there are differences in the spatial localization of the two languages, depending upon the time at which the language was acquired [97,98] and that specific regions are active during language switching. In early bilingual Spanish-English speakers, the two languages are represented in overlapping areas, and the switching is associated with changes in general executive attentional systems [97]. In late bilinguals, the spatial representation of the first and second language can be sepa- rated within the language-sensitive Broca's area of the frontal lobe [98]. However, no separation was found in the languagesensitive Wernicke's area in the temporal lobe.

\subsection{Auditory perception of emotions}

The auditory system has rich connections to limbic structures and has a great ability to convey emotional contents [99-101]. Auditory recognition of fear is reduced in patients with bilateral lesions of the amygdalae [100] or hippocampi [101], limbic structures that are clearly related to emotional processing. Normal subjects engaged in a task to discriminate words based on their expressed emotional tone showed bilateral activation specifically in the right inferior frontal lobe and increased activity in the right anterior auditory cortex, as compared to neutral acoustic stimulation [102]. Threatening auditory stimuli activate the retrosplenial portion of the left cingulate gyrus [103].

In a very recent study, the simple variation of sound amplitude along time, mimicking looming sounds, has demonstrated a great potential to activate brain structures related to attention [104].

\section{Future improvements in auditory fMRI research}

Two main research lines appear particularly promising in the panorama of auditory fMRI research. They both concern methodological improvements, even if from very different points of view, yet converging in the common application to the auditory system and bearing the potential of a reciprocal potentiation in their results. The first promising line of research pertains to the development of MRI techniques able to reduce the stimulation of the auditory cortex from gradient noise. In this direction, the most interesting perspective appears to be the development of "silent" (or less noisy) sequences for fMRI. As discussed above, this cannot be accomplished without reducing the efficiency in image acquisition. Nonetheless, a compromise can be worked out, capable of saving as much efficiency as possible while, at the same time, reducing gradient noise.

The second line of research consists of new perspectives in the neurophysiological interpretation of fMRI data concerning the auditory cortex. As a known limitation in employing fMRI data for interpreting the regional neurophysiology, the use of "inferential" models for the statistical voxel-by-voxel analysis of temporal behavior only allows verification of the presence of those dynamics included in the models. A complete description of neurovascular phenomena, allowing one to build exact models of what happens at the neuronal level, is probably still far in the future.

An interesting alternative is to examine the data without formulating "a priori models" through methods that allow the automatic decomposition of the spatiotemporal fMRI datasets into "components" that are constrained to be independent from each other in the spatial or temporal distribu- 

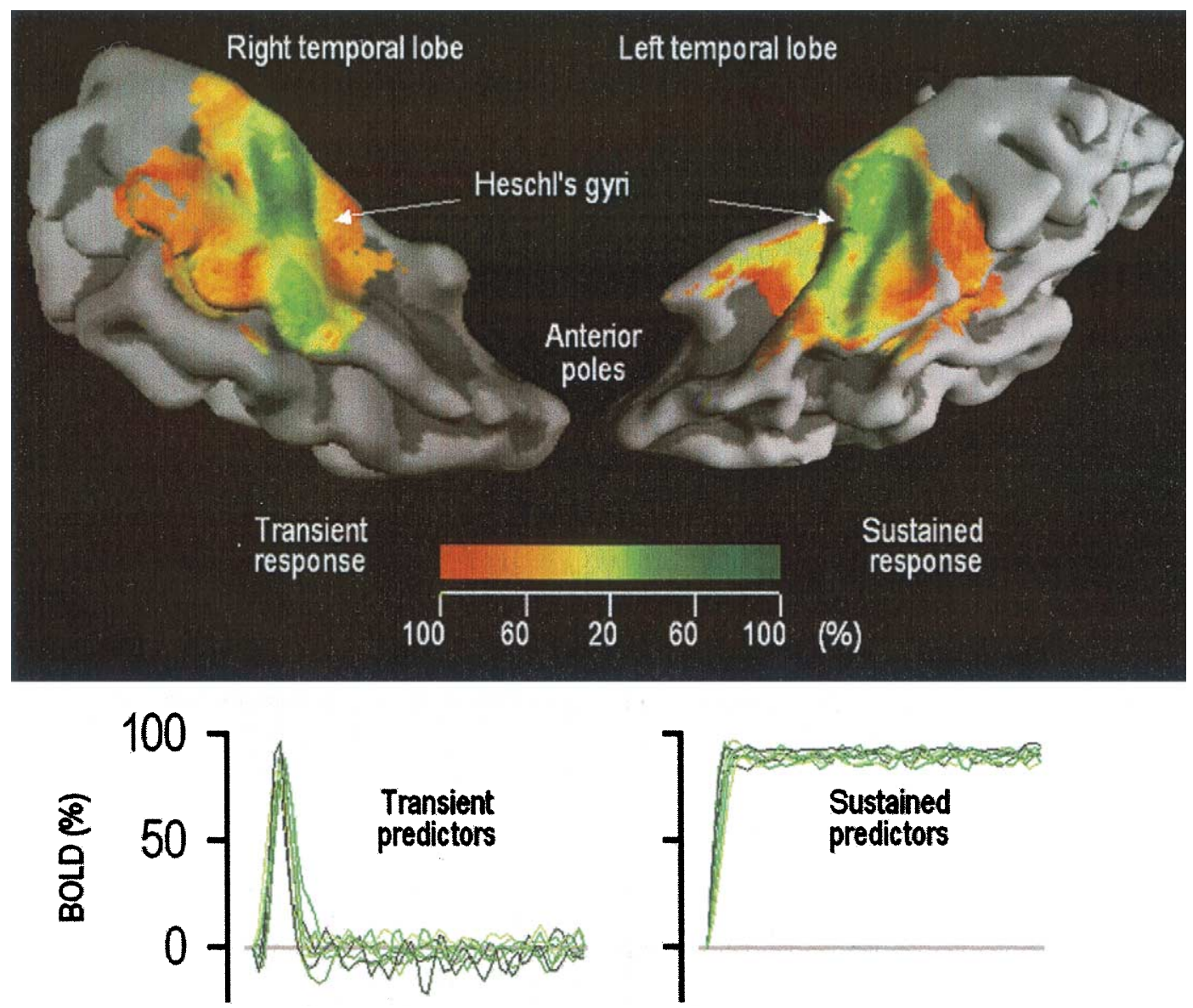

Fig. 3. Surface representation of isolated temporal lobes. A blind temporal decomposition of fMRI data from a pulsed tone stimulation in silence has been carried out through spatial and temporal Independent Component Analysis. Two main behavior models were present, showing a transient and a sustained response to tonal stimulation. These two models corresponded spatially to the subdivision between "core" and "belt" auditory processing. The sustained component (green color) corresponded to Heschl gyrus, while the transient component (red color) corresponded to the planum temporale and the planum polare. Reprinted with permission from: Seifritz E, Esposito F, Hennel F, et al. Spatiotemporal pattern of neural processing in the human auditory cortex. Science 2002;297:1706-8. Copyright 2002 American Association for the Advancement of Science.

tion. These methods convey astonishingly important research perspectives, since they allow researchers, for the first time, to find in the data what is not known in advance, and thus cannot formalize into inferential models. While this approach is potentially applicable to many brain regions, the first application has concerned the separation of spatiotemporal clusters of activity within the temporal cortex, sorting out that two fundamental operational modes can be identified. Their differentiation in space strictly resembles the distinction between "core" and "belt" processing, while the differences in their temporal behaviors highlight the tight constraints that force the auditory cortex to a careful temporal analysis of the world of sounds, where the temporal dimension of the percept assumes a role of primary importance [105-107] (Fig. 3).

\section{References}

[1] Ogawa S, Lee TM, Kay AR, Tank DW. Brain magnetic resonance imaging with contrast dependent on blood oxygenation. Proc Natl Acad Sci USA 1990;87:9868-72.
[2] Kwong KK, Belliveau JW, Chesler DA, Goldberg IE, Weisskopf RM, Boncelet BP, Kennedy DN, Hoppel BE, Cohen MS, Turner R, Cheng HM, Brady TJ, Rosen BR. Dynamic magnetic resonance imaging of human brain activation activity during primary sensory stimulation. Proc Natl Acad Sci USA 1992;89:5675-9.

[3] Bandettini PA, Wong EC, Hinks RS, Tikofsky RS, Hyde JS. Time course EPI of human brain function during task activation. Magn Reson Med 1992;25:390-7.

[4] Campain R, Minckler J. A note on the gross configurations of the human auditory cortex. Brain Lang 1976;3:318-23.

[5] Talairach P, Tournoux J. A stereotactic coplanar atlas of the human brain. Stuttgart: Thieme, 1988.

[6] Villringer A, Dirnagl U. Coupling of brain activity and cerebral blood flow: basis of functional neuroimaging. Cerebrovasc Brain Metab Rev 1995;7:240-76.

[7] Grimm C, Schreiber M, Kristeva-Feige R, Mergner T, Hennig J, Lucking $\mathrm{CH}$. A comparison between electric source localisation and fMRI during somatosensory stimulation. Electroencephalogr Clin Neurophysiol 1998;106:22-9.

[8] Linden DE, Prvulovic D, Formisano E, Vollinger M, Zanella FE, Goebel R, Dierks T. The functional neuroanatomy of target detection: an fMRI study of visual and auditory oddball tasks. Cereb Cortex 1999;9:815-23.

[9] Kim DS, Duong TQ, Kim SG. High-resolution mapping of isoorientation columns by fMRI. Nat Neurosci 2000;3:164-9. 
[10] Saldana E, Merchan MA. Intrinsic and commissural connections of the rat inferior colliculus. J Comp Neurol 1992;319:417-37.

[11] Glendenning KK, Brunso-Bechtold JK, Thompson GC, Masterton RB. Ascending auditory afferents to the nuclei of the lateral lemniscus. J Comp Neurol 1981;197:673-703.

[12] Pandya DN, Rosene DL, Doolittle AM. Corticothalamic connections of auditory-related areas of the temporal lobe in the rhesus monkey. J Comp Neurol 1994;345:447-71.

[13] Duvernoy HM. Three-dimensional sectional anatomy with MRI and blood supply. New York: Springer-Verlag, 1999.

[14] Saleem KS, Suzuki W, Tanaka K, Hashikawa T. Connections between anterior inferotemporal cortex and superior temporal sulcus regions in the macaque monkey. J Neurosci 2000;20:5083-101.

[15] Minckler J. Introduction to neuroscience. St. Louis: Mosby, 1972.

[16] Merzenich MM, Brugge JF. Representation of the cochlear partition of the superior temporal plane of the macaque monkey. Brain Res 1973;50:275-96.

[17] Morel A, Garraghty PE, Kaas JH. Tonotopic organization, architectonic fields, and connections of auditory cortex in macaque monkeys. J Comp Neurol 1993;335:437-59.

[18] Kaas JH, Hackett TA. Subdivisions of auditory cortex and levels of processing in primates. Audiol Neurootol 1998;3:73-85.

[19] Kaas JH, Hackett TA, Tramo MJ. Auditory processing in primate cerebral cortex. Curr Opin Neurobiol 1999;9:164-70.

[20] Galaburda A, Sanides F. Cytoarchitectonic organization of the human auditory cortex. J Comp Neurol 1980;190:597-610.

[21] Rauschecker JP, Tian B, Hauser M. Processing of complex sounds in the macaque nonprimary auditory cortex. Science 1995;268:111-4.

[22] Rauschecker JP. Cortical processing of complex sounds. Curr Opin Neurobiol 1998;8:516-21.

[23] Romanski LM, Tian B, Fritz J, Mishkin M, Goldman-Rakic PS, Rauschecker JP. Dual streams of auditory afferents target multiple domains in the primate prefrontal cortex. Nat Neurosci 1999;2: $1131-6$.

[24] Bushara KO, Weeks RA, Ishii K, Catalan MJ, Tian B, Rauschecker JP, Hallett M. Modality-specific frontal and parietal areas for auditory and visual spatial localization in humans. Nat Neurosci 1999; 2:759-66.

[25] Hedeen RA, Edelstein WA. Characterization and prediction of gradient acoustic noise in MR imagers. Magn Reson Med 1997;37:710.

[26] Ulmer JL, Biswal BB, Yetkin FZ, Mark LP, Mathews VP, Prost RW, Estkowski LD, McAuliffe TL, Haughton VM, Daniels DL. Cortical activation response to acoustic echo planar scanner noise. J Comput Assist Tomogr 1998;22:111-9.

[27] Bandettini PA, Jesmanowicz A, Van Kylen J, Birn RM, Hyde JS. Functional MRI of brain activation induced by scanner acoustic noise. Magn Reson Med 1998;39:410-6.

[28] Hall DA, Summerfield AQ, Goncalves MS, Foster JR, Palmer AR, Bowtell RW. Time-course of the auditory BOLD response to scanner noise. Magn Reson Med 2000;43:601-6.

[29] Ulmer JL, Biswal BB, Mark LP, Mathews VP, Prost RW, Millen SJ, Garman JN, Horzewski D. Acoustic echoplanar scanner noise and pure tone hearing thresholds: the effects of sequence repetition times and acoustic noise rates. J Comput Assist Tomogr 1998;22:480-6.

[30] Shah NJ, Jancke L, Grosse-Ruyken ML, Muller-Gartner HW. Influence of acoustic masking noise in fMRI of the auditory cortex during phonetic discrimination. J Magn Reson Imaging 1999;9:1925 .

[31] Scheich H, Baumgart F, Gaschler-Markefski B, Tegeler C, Tempelmann C, Heinze HJ, Schindler F, Stiller D. Functional magnetic resonance imaging of a human auditory cortex area involved in foreground-background decomposition. Eur J Neurosci 1998;10: 803-9.
[32] Friston KJ, Price CJ, Fletcher P, Moore C, Frackowiak RSJ, Dolan R J. The trouble with cognitive subtraction. Neuroimage 1996;4:97_ 104.

[33] Hennel F, Girard F, Loenneker T. "Silent" MRI with soft gradient pulses. Magn Reson Med 1999;42:6-10.

[34] Hennig J, Hodapp M. Burst imaging. MAGMA 1993;1:39-48.

[35] Jakob PM, Schlaug G, Griswold M, Lovblad KO, Thomas R, Ives JR, Matheson JK, Edelman RR. Functional burst imaging. Magn Reson Med 1998;40:614-21.

[36] Chen CK, Chiueh TD, Chen JH. Active cancellation system of acoustic noise in MR imaging. IEEE Trans Biomed Eng 1999;46: 186-91.

[37] Ravicz ME, Melcher JR, Kiang NY. Acoustic noise during functional magnetic resonance imaging. J Acoust Soc Am 2000;108: 1683-96.

[38] Cohen MS. Parametric analysis of fMRI data using linear systems methods. Neuroimage 1997;6:93-103.

[39] Scheffler K, Seifritz E, Haselhorst R, Bilecen D. Titration of the BOLD effect. Separation and quantitation of blood volume and oxygenation changes in the human cerebral cortex during neuronal activation and ferumoxide infusion. Magn Reson Med 1999;42: 829-36.

[40] Scheffler K, Bilecen D, Schmid N, Tschopp K, Seelig J. Auditory cortical responses in hearing subjects and unilateral deaf patients as detected by functional magnetic resonance imaging. Cereb Cortex 1998;8:156-63.

[41] Bilecen D, Radü EW, Scheffler K. The MR tomograph as a sound generator. fMRI tool for the investigation of the auditory cortex. Magn Reson Med 1998;40:934-7.

[42] Bilecen, D, Scheffler, K, Schmid, N, Tschopp, K, Seelig, J. Cerebral compensation mechanism of the auditive system detected by fMRI [Abstract]. Proc ISMRM, Vol. 1. New York, 1996. p. 1841.

[43] Edmister WB, Talavage TM, Ledden PJ, Weisskoff RM. Improved auditory cortex imaging using clustered volume acquisitions. Hum Brain Mapping 1999;7:89-97.

[44] Hall DA, Haggard MP, Akeroyd MA, Palmer AR, Summerfield AQ, Elliott MR, Gurney EM, Bowtell RW. "Sparse" temporal sampling in auditory fMRI. Hum Brain Mapp 1999;7:213-23.

[45] Robson MD, Dorosz JL, Gore JC. Measurements of the temporal fMRI response of the human auditory cortex to trains of tones. Neuroimage 1998;7:185-98.

[46] Belin P, Zatorre RJ, Hoge R, Evans AC, Pike B. Event-related fMRI of the auditory cortex. Neuroimage 1999;10:417-29.

[47] Di Salle F, Formisano E, Seifritz E, Linden DEJ, Scheffler K, Saulino C, Tedeschi G, Zanella FE, Pepino A, Goebel R, Marciano E. Functional fields in human auditory cortex revealed by timeresolved fMRI without interference of EPI noise. Neuroimage 2001; $13: 328-38$

[48] Eden GF, Joseph JE, Brown HE, Brown CP, Zeffiro TA. Utilizing hemodynamic delay and dispersion to detect fMRI signal change without auditory interference: the behavior interleaved gradients technique. Magn Reson Med 1999;41:13-20.

[49] Hennel F, Bolo N, Namer I, Nedelec JF, Macher JP. Direct measurement of BOLD response to the acoustic noise of EPI gradients [Abstract]. Proc ESMRM B, Vol. 1. Geneva, 1998. p. 218.

[50] Binder JR, Rao SM, Hammeke TA, Yetkin FZ, Jesmanowicz A, Bandettini PA, Wong EC, Estkowski LD, Goldstein MD, Haughton VM, Hyde JS. Functional magnetic resonance imaging of human auditory cortex. Ann Neurol 1994;35:662-72.

[51] Jancke L, Shah NJ, Posse S, Grosse-Ryuken M, Muller-Gartner HW. Intensity coding of auditory stimuli: an fMRI study. Neuropsychologia 1998;36:875-83.

[52] Pugh KR, offywitz BA, Shaywitz SE, Fulbright RK, Byrd D, Skudlarski P, Shankweiler DP, Katz L, Constable RT, Fletcher J, Lacadie C, Marchione K, Gore JC. Auditory selective attention: an fMRI investigation. Neuroimage 1996;4:159-73. 
[53] Binder JR, Rao SM, Hammeke TA, Frost JA, Bandettini PA, Hyde JS. Effects of stimulus rate on signal response during functional magnetic resonance imaging of auditory cortex. Brain Res Cogn Brain Res 1994;2:31-8.

[54] Tanaka H, Fujita N, Watanabe Y, Hirabuki N, Takanashi M, Oshiro Y, Nakamura H. Effects of stimulus rate on the auditory cortex using fMRI with 'sparse' temporal sampling. Neuroreport 2000;11:2045-9.

[55] Melcher JR, Sigalovsky IS, Guinan JJ, Levine RA. Lateralized tinnitus studied with functional magnetic resonance imaging. abnormal inferior colliculus activation. J Neurophysiol 2000;83:1058-72.

[56] Loveless N, Vasama J, Mäkelä J, Hari R. Human auditory cortical mechanisms of sound lateralisation: IIIMonaural and binaural shift responses. Hear Res 1994;81:91-9.

[57] Konishi M, Takahashi TT, Wagner H, Sullivan WE, Sullivan WE, Carr CE. Neurophysiological and anatomical substrates of sound localization in the owl. In: Edelman GM, Gall WE, Cowan WM. Auditory function: neurobiological bases of hearing. New York: Wiley, 1988. p. 721-45.

[58] Guimaraes AR, Melcher JP, Talavage TM, Baker JR, Ledden P, Rosen BR, Kiang NYS, Fullerton BC, Weisskoff RM. Imaging subcortical auditory activity in humans. Hum Brain Mapping 1998; 6:33-41.

[59] Naatanen R. Mismatch negativity: clinical research and possible applications. Int J Psychophysiol 2003;48:179-88.

[60] Mustovic, H, Scheffler, K, Di Salle, F, Esposito, F, Neuhoff, JG, Hennig, J, Seifritz, E. Temporal integration auditory events in human planum temporale probed by silent period in sound pattern. Neuroimage 2003;20:429-34.

[61] Merzenich MM, Knight PL, Roth GL. Representation of cochlea within primary auditory cortex in the cat. J Neurophysiol 1975;38: 231-49.

[62] Romani GL, Williamson SJ, Kaufman L. Tonotopic organization of the human auditory cortex. Science 1982;216:1339-40.

[63] Verkindt C, Bertrand O, Perrin F, Echallier JF, Pernier J. Tonotopic organization of the human auditory cortex: N100 topography and multiple dipole model analysis. Electroencephalogr Clin Neurophysiol 1995;96:143-56.

[64] Pantev C, Bertrand O, Eulitz C, Verkindt C, Hampson S, Schuierer $\mathrm{G}$, Elbert T. Specific tonotopic organizations of different areas of the human auditory cortex revealed by simultaneous magnetic and electric recordings. Electroencephalogr Clin Neurophysiol 1995;94:2640.

[65] Arlinger S, Elberling C, Bak C, Kofoed B, Lebech J, Saermark K. Cortical magnetic fields evoked by frequency glides of a continuous tone. Electroencephalogr Clin Neurophysiol 1982;54:642-53.

[66] Tuomisto T, Hari R, Katila R, Poutanen T, Varpula T. Studies of auditory evoked magnetic and electric responses: modality specificity and modeling. Nuovo Cimento 1983;2D:471-83.

[67] Pantev C, Hoke M, Lehnertz K, Lutkenhoner B, Anogianakis G, Wittkowski W. Tonotopic organization of the human auditory cortex revealed by transient auditory evoked magnetic fields. Electroencephalogr Clin Neurophysiol 1988;69:160-70.

[68] Elberling C, Bak C, Kofoed B, Lebech J, Saermark K. Auditory magnetic fields: source location and 'tonotopical organization' in the right hemisphere of the human brain. Scand Audiol 1982;11:61-5.

[69] Tiitinen H, Alho K, Huotilainen M, Ilmoniemi RJ, Simola J, Naatanen R. Tonotopic auditory cortex and the magnetoencephalographic (MEG) equivalent of the mismatch negativity. Psychophysiology 1993;30:537-40.

[70] Yamamoto T, Uemura T, Llinas R. Tonotopic organization of human auditory cortex revealed by multi-channel SQUID system. Acta Otolaryngol 1992;112:201-4.

[71] Yamamoto T, Williamson SJ, Kaufman L, Nicholson C, Llinas R. Magnetic localization of neuronal activity in the human brain. Proc Natl Acad Sci USA 1988;85:8732-6.
[72] Bertrand, O, Perrin, F, Pernier, J. Evidence for a tonotopic organization of the auditory cortex observed with auditory evoked potentials. Acta Otolaryngol Suppl 1991;491:116-23.

[73] Howard MA, Volkov IO, Abbas PJ, Damasio H, Ollendieck MC, Granner MA. A chronic microelectrode investigation of the tonotopic organization of human auditory cortex. Brain Res 1996;724: $260-4$.

[74] Muhlnickel W, Elbert T, Taub E, Flor H. Reorganization of auditory cortex in tinnitus. Proc Natl Acad Sci USA 1998;95:10340-3.

[75] Lauter JL, Herscovitch P, Formby C, Raichle ME. Tonotopic organization in human auditory cortex revealed by positron emission tomography. Hear Res 1985;20:199-205.

[76] Bilecen D, Scheffler K, Schmid N, Tschopp K, Seelig J. Tonotopic organization of the human auditory cortex as detected by BOLD fMRI. Hear Res 1998;126:19-27.

[77] Wessinger CM, Buonocore MH, Kussmaul CL, Mangun GR. Tonotopy in human auditory cortex examined with functional magnetic resonance imaging. Hum Brain Mapping 1997;5:18-25.

[78] Lantos G, Liu G, Shafer V, Knuth K, Vaughan H. Tonotopic organization of primary auditory cortex: an fMRI study [Abstract]. Neuroimage 1997;5:S174.

[79] Strainer JC, Ulmer JL, Yetkin FZ, Haughton VM, Daniels DL, Millen SJ. Functional MR of the primary auditory cortex: an analysis of pure tone activation and tone discrimination. AJNR Am J Neuroradiol 1997;18:601-10.

[80] Talavage RM, Ledden PJ, Sereno MI, Rosen BR, Dale AM. Multiple phase-encoded tonotopic maps in human auditory cortex [Abstract]. Neuroimage 1997;5:S8.

[81] Talavage RM, Benson RR, Galaburda AM, Rosen BR. Evidence of multiple tonotopic fields in human auditory cortex [Abstract]. Proc ISMRM 1996;4:1842.

[82] Yang Y, Engelien A, Engelien W, Xu S, Stern E, Silbersweig DA. A silent event-related functional MRI technique for brain activation studies without interference of scanner acoustic noise. Magn Reson Med 2000;43:185-90.

[83] Engelien A, Yang Y, Engelien W, Zonana J, Stern E, Silbersweig DA. Physiological mapping of human auditory cortices with a silent event-related fMRI technique. Neuroimage 2002;16:944-53.

[84] Griffiths TD. Human complex sound analysis. Clin Sci (Colch) 1999;96:231-4.

[85] Griffiths TD, Rees A, Witton C, Shakir RA, Henning GB, Green GG. Evidence for a sound movement area in the human cerebral cortex. Nature 1996;383:425-7.

[86] Pavani F, Macaluso E, Warren JD, Driver J, Griffiths TD. A common cortical substrate activated by horizontal and vertical sound movement in the human brain. Curr Biol 2002;12:1584-90.

[87] Warren JD, Zielinski BA, Green GG, Rauschecker JP, Griffiths TD. Perception of sound-source motion by the human brain. Neuron 2002;34:139-48.

[88] Griffiths TD, Green GG, Rees A, Rees G. Human brain areas involved in the analysis of auditory movement. Hum Brain Mapping 2000;9:72-80.

[89] Lewis JW, Beauchamp MS, DeYoe EA. A comparison of visual and auditory motion processing in human cerebral cortex. Cereb Cortex 2000;10:873-88.

[90] Weeks R, Horwitz B, Aziz-Sultan A, Tian B, Wessinger CM, Cohen LG, Hallett M, Rauschecker JP. A positron emission tomographic study of auditory localization in the congenitally blind. J Neurosci 2000;20:2664-72.

[91] Belin P, Zatorre RJ, Lafaille P, Ahad P, Pike B. Voice-selective areas in human auditory cortex. Nature 2000;403:309-12.

[92] Binder JR, Frost JA, Hammeke TA, Bellgowan PS, Springer JA, Kaufman JN, Possing ET. Human temporal lobe activation by speech and nonspeech sounds. Cereb Cortex 2000;10:512-28.

[93] Halgren E, Dale AM, Sereno MI, Tootell RB, Marinkovic K, Rosen BR. Location of human face-selective cortex with respect to retinotopic areas. Hum Brain Mapping 1999;7:29-37. 
[94] Binder JR, Frost JA, Hammeke TA, Cox RW, Rao SM, Prieto T. Human brain language areas identified by functional magnetic resonance imaging. J Neurosci 1997;17:353-62.

[95] Friederici AD, Meyer M, von Cramon DY. Auditory language comprehension: an event-related fMRI study on the processing of syntactic and lexical information. Brain Lang 2000;74:289-300.

[96] Friederici AD, Opitz B, von Cramon DY. Segregating semantic and syntactic aspects of processing in the human brain: an fMRI investigation of different word types. Cereb Cortex 2000;10:698-705.

[97] Hernandez AE, Martinez A, Kohnert K. In search of the language switch. An fMRI study of picture naming in Spanish-English bilinguals. Brain Lang 2000;73:421-31.

[98] Kim KH, Relkin NR, Lee KM, Hirsch J. Distinct cortical areas associated with native and second languages. Nature 1997;388: $171-4$.

[99] Büchel C, Dolan RJ. Classical fear conditioning in functional neuroimaging. Curr Opin Neurobiol 2000;10:219-23.

[100] Scott SK, Young AW, Calder AJ, Hellawell DJ, Aggleton JP, Johnson M. Impaired auditory recognition of fear and anger following bilateral amygdala lesions. Nature 1997;385:254-7.

[101] Ghika-Schmid F, Ghika J, Vuilleumier P, Assal G, Vuadens P, Scherer K, Maeder P, Uske A, Bogousslavsky J. Bihippocampal damage with emotional dysfunction: impaired auditory recognition of fear. Eur Neurol 1997;38:276-83.

[102] Buchanan TW, Lutz K, Mirzazade S, Specht K, Shah NJ, Zilles K, Jancke $\mathrm{L}$. Recognition of emotional prosody and verbal components of spoken language: an fMRI study. Brain Res Cogn Brain Res 2000;9:227-38.

[103] Maddock RJ, Buonocore MH. Activation of left posterior cingulate gyrus by the auditory presentation of threat-related words: an fMRI study. Psychiatry Res 1997;75:1-14.

[104] Seifritz E, Neuhoff JG, Bilecen D, Scheffler K, Mustovic H, Schachinger $\mathrm{H}$, Elefante R, Di Salle F. Neural processing of auditory looming in the human brain. Curr Biol 2002;12:2147-51.

[105] Seifritz E, Esposito F, Neuhoff JG, Di Salle F. Response: sound analysis in auditory cortex-from temporal decomposition to perception. Trends Neurosci 2003;26:231-2.

[106] Seifritz E, Esposito F, Hennel F, Mustovic H, Neuhoff JG, Bilecen D, Tedeschi G, Scheffler K, Di Salle F. Spatiotemporal pattern of neural processing in the human auditory cortex. Science 2002;297: $1706-8$.

[107] Zatorre RJ. Sound analysis in auditory cortex. Trends Neurosci 2003;26:229-30. 